Fecha de recepción: marzo 2020 Fecha de aceptación: abril 2020 Versión final: junio 2020

\section{Las derechas hechas meme en Argentina y Brasil (2015-2019): un análisis sobre los contenidos de humor político en el contexto de gobiernos conservadores}

Ana Belén Mercado ${ }^{(1)}$ y Enzo Andrés Scargiali ${ }^{(2)}$

\begin{abstract}
Resumen: Durante los últimos años, la masificación del uso de las nuevas tecnologías habilitó canales de comunicación y circulación de la información de manera inmediata, lo que, a su vez, tuvo consecuencias en las formas de producción, circulación y consumo del humor. Entre otros, se popularizaron difrentes formas de humor, los ya conocidos "memes", que consisten en imágenes intervenidas a modo de parodia, sátira o ridiculización de figuras públicas, que abarcan desde presidentes y presidentas hasta líderes religiosos, pasando por referentes de distintos espacios políticos.

El objetivo de este artículo es analizar los contenidos de memes sobre las derechas como expresión de humores sociales y de climas políticos en Argentina y Brasil entre 2015 y 2019. En particular, se trabajó con memes que circularon por redes sociales como Twitter, Instagram y Facebook, entre 2015 y 2019 en Brasil y Argentina. Para ordenar nuestro análisis, seleccionamos algunos de los hechos políticos de mayor repercusión mediática durante el período.

Para finalizar, esbozamos una reflexión sobre los memes políticos como nuevos formatos humorísticos, los momentos en los que surgen, su inmediatez y efecto a corto plazo y su contribución a la reproducción de ciertos humores sociales.
\end{abstract}

Palabras claves: memes - humor político - Brasil - Argentina.

[Resúmenes en inglés y portugués en las páginas 293-294]

(1) Ana Belén Mercado es Licenciada en Sociología por la Facultad de Ciencias Sociales, Universidad de Buenos Aires. Maestranda en Estudios Sociales Latinoamericanos (Facultad de Ciencias Sociales, UBA). Becaria doctoral de CONICET, bajo la dirección de Lorena Soler en el marco del UBACyT "Think tanks, agenda de cambio y política en Argentina, Colombia y Brasil".

(2) Enzo Andrés Scargiali es Licenciado y Profesor de Enseñanza Secundaria, Normal y Especial en Sociología por la Facultad de Ciencias Sociales, Universidad de Buenos Aires. Maestrando en Estudios Sociales Latinoamericanos (Facultad de Ciencias Sociales, UBA). Becario de posgrado de la Universidad de Buenos Aires bajo la dirección de Lorena Soler en el marco del UBACyT "Think tanks, agenda de cambio y política en Argentina, Colombia y Brasil". 


\section{Introducción}

La expansión de las tecnologías de la información y la comunicación y el surgimiento de nuevas plataformas de generación y distribución de contenidos -las redes sociales-, en palabras de Urresti, Linne y Basile (2015), han producido una revolución en los diversos planos que conforman a las sociedades latinoamericanas: desde el ámbito de la economía y la producción, los poderes del Estado, hasta la cultura y la comunicación. Al mismo tiempo, las sociedades a lo largo y ancho del continente interactúan cada vez más y con mayor frecuencia a través de celulares y otros artefactos digitales de comunicación. En efecto, el ámbito laboral, los lugares de estudio, el hogar, el transporte público y todos los espacios se han convertido en el entramado real que posibilita la circulación de contenidos digitales -y sociales- en el paisaje cotidiano de las ciudades latinoamericanas. En efecto, los límites entre lo real y lo digital se acortan y los contenidos digitales se convierten en herramientas políticas que contribuyen a expresar un determinado clima político. Por su parte, desde mediados de 2015, sea a partir de triunfos electorales (Chile, Argentina, Colombia) o de golpes de Estado a partir de procesos de judicialización de la política (Paraguay, Brasil), las derechas en América Latina han conquistado el poder de gobierno o se han afianzado en él. Como contrapartida, los proyectos políticos progresistas o posneoliberales continentales han retrocedido considerablemente. En este marco político y social en América Latina han cobrado relevancia los estudios acerca de la producción de humor acerca de las políticas implementadas por las derechas en el gobierno.

En este clima particular, los memes son una nueva forma de expresión. La producción de contenidos humorísticos que cuestionan a sectores de poder no son una novedad, como veremos más adelante. Sin embargo, la forma que estos contenidos adoptan en la actualidad, reconocidos bajo el nombre de "memes" y montados a través de las redes sociales, presentan cuestiones novedosas respecto de las formas de hacer (y compartir) el humor. Concebimos que existe una triangulación entre tres elementos que coadyuvan en este fenómeno. El primero de ellos es el contexto político de avance de las derechas en América Latina que ya mencionamos, el segundo es el humor como herramienta de lucha ideológica y cuestionamiento del poder establecido y el tercero son las tecnologías de la comunicación, que operan como plataformas a través de las cuales este tipo de humor se produce y circula.

Respecto de los memes como formas de expresión de ideologías, debemos decir que los mismos pueden ser (y son) utilizados tanto por las izquierdas como por las derechas, a modo de herramientas en disputa por los sentidos. Sin embargo, coincidimos con Reguillo (2018) quien plantea que "los memes de la derecha no logran la suficiente eficacia irónica, porque es tan fuerte su desprecio por "lo otro" que no llegan al lugar de la ironía", en tanto que apropiarse de una imagen se vuelve una manera sutil de cuestionar al poder establecido. Es por ello que en este trabajo nos abocaremos al análisis sobre la producción y el contenido de los memes sobre las derechas en Argentina y Brasil (2015-2019).

El objetivo del trabajo es indagar acerca de la forma en que los memes han logrado expresar el clima político y social ante los gobiernos de derecha en Argentina y Brasil y dar cuenta de alguna de sus características en común. Si bien, intentaremos analizar ambos países, nos focalizaremos en el argentino. Como destacamos luego, el acceso a los me- 
mes en la mayoría de los casos -a excepción de aquellos que son reflejados por medios masivos de comunicación o portales de noticias- se realiza a través de ámbitos privados de comunicación como son Whatsapp o Telegram. En este sentido, las características de su circulación ha sido una dificultad a la hora de reunir mayor cantidad de información acerca del caso brasileño. Sin embargo, creemos de relevancia su incorporación ya que nos permiten analizar con mayor profundidad al objeto de estudio.

Por último, es válido aclarar que el trabajo es de carácter exploratorio y se basa en casos emergentes y coyunturales al momento que fue realizado el relevamiento de datos. En este sentido, si bien consideramos que el análisis puede replicarse a otros memes, no persigue una intención de generalizar, ya que la dinámica de su producción y circulación se encuentra en constante mutación y atravesada por la coyuntura económica, política y social de cada país.

Para ordenar nuestro análisis seleccionamos algunos de los hechos políticos que alcanzaron repercusión mediática durante el periodo de recolección de información. En este sentido, se trata de hechos o situaciones con impacto social puesto que ocuparon un espacio central en los medios masivos de comunicación, portales de internet y redes sociales.

\section{¿Qué se ha estudiado sobre los memes hasta el momento?}

El estudio sobre los memes es un campo que aún encuentra vacancia en diferentes áreas de investigación en América Latina. Si bien existen trabajos desde las teorías de la comunicación en México (García Huerta, 2014; Vélez, 2012) y algunos artículos sobre la relación entre memes, humor y política en Brasil (Arango Pinto, 2015; Chagas, 2018), su estudio no ha sido abordado en el caso argentino, así como tampoco en el resto de los países del continente. Sin embargo, la genealogía del meme se remonta a la década de 1970. Dawkins (1979) fue el primero en utilizar el término; realizando un juego de palabras con "gene" (gen), lo asocia a una forma de transmisión de información a través del aprendizaje. Como destaca Arango Pinto (2015), las ideas, los hábitos y las tradiciones van comunicándose. De esta forma, el lenguaje, los conocimientos, mitos y ritos, son aprendidos. Una idea más ajustada del concepto lo define como "unidades de replicación culturales a partir del cual la cultura evoluciona".

En la actualidad, atravesados por la masificación del uso de las redes sociales, los memes adquieren un nuevo lugar en la comunicación. Son entendidos como cualquier texto, imagen o video que, por su sentido humorístico, puede ser replicado en las redes sociales. Vélez (2012) agrega que constituyen fenómenos efímeros y “pegajosos" que se parodian y repiten hasta el punto de que sus orígenes y significado original se vuelven difusos y mutilados.

Por su parte, los memes políticos comparten algunas de sus características con las caricaturas políticas, fundamentalmente en lo que refiere a los mecanismos del humor, pero hay diferencias sustanciales entre ambos que responden a cuestiones no sólo políticas, sino tecnológicas. Las caricaturas políticas son publicadas en revistas, diarios u otros me- 
dios impresos y sus autores y autoras, identificables; mientras que los memes son, por lo general, anónimos en cuanto a su producción -e intervención-, masivos y "viralizados" en lo que refiere a su difusión. En este sentido entendemos como factor clave las plataformas en la que circulan -Internet y, en particular, las redes sociales.

Otros autores han estudiado el humor producido desde las derechas, sea en otros contextos latinoamericanos o en la actualidad. En este grupo identificamos el trabajo de Soler (2017), que analizó el uso del humor político por parte del régimen stronista en Paraguay para ridiculizar y deslegitimar los órdenes socialistas y así "recrear una comunidad/ identidad y, por lo tanto, una legitimidad sobre la guerra que se estaba librando contra el comunismo" (p. 203). Por otro lado, en la actualidad, encontramos trabajos que, en un sentido similar al mencionado, atribuyen a los memes el ser una herramienta utilizada por las extremas derechas para presentar sus discursos de odio como ironías humorísticas. Así lo formula Solano (2018) para el caso del ascenso de Bolsonaro en Brasil. Sin embargo, nuestra intención es abordar el análisis de los memes como expresiones de un clima político que busca ironizar sobre las figuras y las ideas de las derechas, desde posiciones contrarias a éstas, con el objeto de ridiculizar a sus principales referentes, deslegitimarlos y disputar los sentidos que las figuras de las derechas reproducen a través de los distintos canales de comunicación.

Para ello, retomamos otra línea de trabajo en la que identificamos estas propuestas. Burkart $(2009,2014)$ ha indagado en varios estudios sobre las formas y las estrategias del humor, fundamentalmente la caricatura, en el contexto de los gobiernos autoritarios y dictatoriales de los años 1970 en América Latina. Soler (2015) se ocupó de pensar el humor político en Paraguay producido desde el pueblo contra el régimen stronista en un contexto político de desgaste de las dictaduras, en el que algunas publicaciones editoriales encontraron el clima para desplegar su "capacidad de trasgresión en tanto se atrevieron a reírse hasta de lo que en ese momento había sido la imagen inmaculada del propio Alfredo Stroessner" (Soler, 2015: 42). Aquí encontramos antecedentes sobre la producción de humor con objetivos políticos de deslegitimación de los órdenes establecidos y canalización de climas sociales contrarios a los gobiernos autoritarios.

Otro aspecto que caracteriza a la caricatura política tradicional y la diferencia de los memes es la ligazón al tiempo y al lugar en que fue realizada, que hace del caricaturista un cronista de la época. Esto convierte a la caricatura en algo que es necesario explicar, describir y contextualizar para que adquiera sentido y resalte lo que no surge a la vista (Bukart, 2014). Soler (2017) agrega que, en la caricatura, debido al tipo de contrato de lectura que establece el dibujante con el lector, se asume que los dibujos están dirigidos a un público con acceso a información actualizada y refinada sobre el contexto, en su caso de estudio, internacional. Los chistes estudiados por la autora apelaban a lectores urbanos que no podían estar aislados, sino que formaban parte de una clara red de intercambio y préstamos con otras clases políticas.

En los memes, algunas de estas consideraciones no tienen lugar, como veremos en los siguientes apartados. Por un lado, si bien los memes no son más que un emergente del contexto -y que sólo tiene efectividad en el momento en que se producen- sus dibujos, videos y frases son de llegada masiva al público que, si bien circula en las redes sociales, ello no implica que se requieran de mayores habilidades para su interpretación. Por este 
motivo, se vuelven herramientas poderosas al momento de la construcción y difusión de agendas políticas. En este sentido, Reguillo (2018) identifica tres herramientas utilizadas en las redes para imponer agendas políticas: los memes, el streaming y el "micrófono humano". El streaming y los memes comparten algunas de sus características. Tanto uno como otros llevan la protesta más allá del territorio donde se genera y trastocan los controles que pretenden ejercer desde los medios de comunicación dominantes y el poder gubernamental. Además, ambos implican competencias tecnológicas para su utilización que, con el paso del tiempo, se han vuelto masivas y de simple utilización para una gran parte de la ciudadanía.

En pocas palabras, los memes sobre política presentan algunas cualidades similares a las de la caricatura política, en tanto que deben ser leídos e interpretados en su contexto de producción para poder ser asimilados, y otras características que los diferencian de aquellas. Fundamentalmente, en lo que refiere a su medio de circulación, a la posibilidad de ser modificados en el proceso de circulación por múltiples usuarios de manera anónima y a la llegada masiva que pueden lograr en un corto plazo, la "viralización".

A partir del marco desarrollado en este apartado, analizamos a continuación los memes seleccionados para nuestro estudio, bajo la premisa de que conforman una nueva forma de producir humor sobre política, con características similares a la tradicional caricatura política, y a la vez, con elementos diferenciadores, los que particularmente intentamos destacar.

\section{Contexto histórico de triunfos de las derechas en América Latina}

En el marco de la expansión de las redes sociales, de nuevas formas de transmisión de la información y de producción del humor, es necesario revisar el contexto histórico en el que se producen y difunden los memes que analizamos en este trabajo, en particular en los casos de Argentina y Brasil entre 2015 y 2019. Resulta clave para comprender el clima político en el que aquellos se producen y circulan, a la vez que nos brinda la posibilidad de reflexionar en torno los conflictos y las disputas por los sentidos que tienen lugar en la actualidad y cómo se desplegó esa lucha por la hegemonía política en los años recientes. En este sentido, el triunfo electoral de Jair Bolsonaro en Brasil en 2018, previo impeachment a la presidenta Dilma Rousseff y encarcelamiento del principal candidato del Partido dos Trabalhadores (PT), Lula da Silva, marca un hito en el ascenso al poder por la vía electoral de una extrema derecha racista, homofóbica, liberal en lo económico y con rasgos autoritarios. En este marco, el protagonismo que adquirió el juez Sérgio Moro, primero como responsable del encarcelamiento de Lula y luego como Ministro de Justicia de Bolsonaro, será un dato clave para interpretar las piezas de humor que analizaremos en el siguiente apartado.

Si bien la llegada al poder de la derecha en Argentina a partir del gobierno de Mauricio Macri (2015) se dio en un contexto muy distinto al del caso brasileño, existeron acciones y políticas de su gobierno que es posible caracterizar como autoritarios. Así, resulta relevante considerar la figura de la Ministra de Seguridad, Patricia Bullrich, quien ha 
expresado discursos y ha implementado políticas de "mano dura" durante su gestión. Los discursos y algunas características asociadas a la personalidad de la ministra han sido objeto de humor en las redes sociales, tal como veremos a continuación.

Los memes analizados en este trabajo tienen como objetivo ironizar sobre las políticas, los discursos o las formas de presentarse ante la sociedad por parte de las derechas en el gobierno. Juegan con los significados de la realidad, resaltando lo que es ignorado u ocultado por los medios de comunicación hegemónicos. Además, se relacionan con la cultura popular -y son producto de esta- a partir de los códigos que utilizan para señalar de modo irónico o satírico los sentidos que se quieren transmitir.

\section{Características y análisis de los memes}

\section{a. Efímeros y circunstanciales}

A continuación, presentaremos algunas de las principales características que destacamos de los memes y sus usos políticos. Por motivo de extensión y por las especificidades propias de lo que aquí indagamos, los memes fueron seleccionados en función de sus vínculos con las derechas y el humor sobre las mismas. Por otro lado, hemos tomado memes que remiten a hechos recientes, aunque su trasfondo se puede contextualizar en el avance de las derechas en los gobiernos de Mauricio Macri en Argentina (2015-2019) y la elección y primer año de la presidencia de Jair Bolsonaro en Brasil (2018-2019); aunque para el caso brasileño el período bajo análisis debe contemplar el impeachment y destitución de la presidenta Dilma Rousseff y el encarcelamiento de Lula, por ser acontecimientos en los que se evidenció el recrudecimiento de las derechas.

Una de las características de los memes se vincula con su carácter efímero y circunstancial. Al ser producidos en un determinado clima político, reflejan el humor social del momento en particular y por ello se encuentran estrechamente ligados a la coyuntura, al tiempo que contribuyen a la reproducción del clima en el que se producen. Sin el contexto político, económico y social de su producción, pierden su sentido y efectividad, como toda pieza humorística. Los memes, al igual que las caricaturas, forman parte de las circunstancias, perdiendo vigencia rápidamente y convirtiéndose en un auxiliar de la información histórica en tanto crónica informal y expresiva de una época, un lugar, un proceso (Romano, 1990).

El meme, para cumplir con su fin, requiere del contexto. Su sentido no es más que la situación coyuntural y los actores a los que hace referencia. Si bien algunas figuras logran trascender al meme, su origen puede verse perdido a partir de la incorporación de capas de nueva información o de la pérdida de vigencia de la discusión pública a la que hace referencia.

Tras la muerte del fiscal Alberto Nisman en enero de 2015, la corporación judicial, encabezada por distintos fiscales de la Nación, realizó una serie de marchas en contra del Gobierno Nacional, que encabezaba Cristina Fernández, en la Plaza del Congreso Nacional. Entre los asistentes, se destacó la presencia de una militante del Partido Radical, quien 
frente a las cámaras realizó un alegato muy pintoresco en recuerdo del fiscal fallecido. Rápidamente, su imagen comenzó a circular por las redes sociales, y se fueron reproduciendo sus frases y llamativas expresiones bajo el nombre de "La señora Bisman" (Figura 1). Si bien, su salto a la fama se dio en el marco de esta manifestación, su perdurabilidad en el tiempo se vio traccionada por la capacidad de transformarse y adaptarse a nuevas coyunturas sociales. Sus frases actualmente forman parte de la jerga cotidiana de adolescentes y jóvenes.

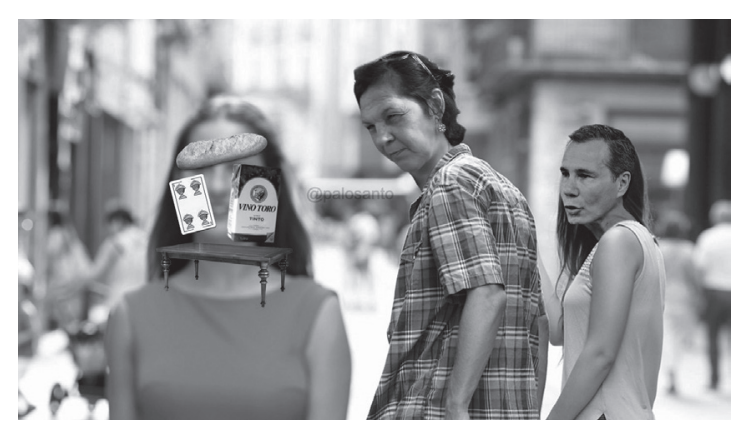

Figura 1. Señora Bisman.

"Al pan, pan, al vino, vino. Sobre las cartas la mesa" es una de las frases de mayor trascendencia de la militante radical apodada "Señora Bisman". En la imagen se la observa acompañada del fiscal Alberto Nisman.

\section{b. Ridiculización del poder}

Como vemos, la transgresión forma parte del humor propio que intentan reproducir los memes. Existen límites difusos entre aquello con lo que se puede hacer humor y aquello con lo que no. Otra de las características de los memes es la apelación a la ridiculización de los factores de poder y sus actores. En este marco, los funcionarios que representan el ala "dura" de las políticas de derecha (represivas y regresivas) son material predilecto para el surgimiento y la difusión de diferentes imágenes donde se los satiriza.

En este punto, nos centraremos en dos figuras relevantes: la Ministra de Seguridad del Gobierno Nacional de Argentina, Patricia Bullrich y el Ministro de Justicia y Seguridad Pública de Brasil, Sergio Moro. Ambos, han cobrado relevancia mediática a partir de sus trayectorias políticas anteriores a alcanzar los cargos de ministros. Bullrich es una reconocida militante política que ha alcanzado cargos ejecutivos y legislativos en diferentes estructuras partidarias. Actualmente, forma parte de la alianza "Juntos por el Cambio" que reúne a Propuesta Republicana, Coalición Cívica y la Unión Cívica Radical. Por su parte, Moro proviene del ámbito judicial, desempeñándose como Juez Federal de Brasil 
por la cuarta región. Su salto mediático se produjo cuando quedó a cargo de la Operación "Lava Jato" que condenó al expresidente brasileño, Luiz Inácio Lula Da Silva, a doce años y once meses de prisión, negándole así la posibilidad de participar en las elecciones presidenciales del año 2018. Tras el triunfo de Jair Messias Bolsonaro en las elecciones, Moro fue designado ministro.
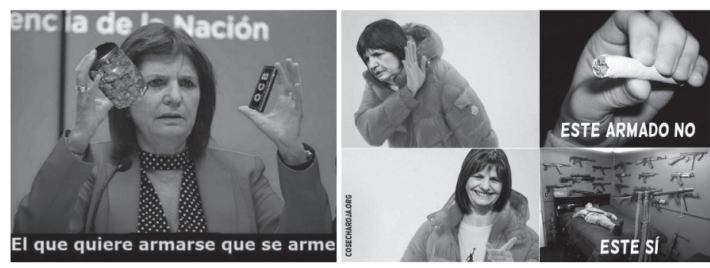

Figura 2. Patricia Bullrich.

"El que quiere armarse que se arme", fue una frase pronunciada por la ministra Patricia Bullrich frente a las cámaras de televisión el 2 de noviembre de 2018. En este contexto, se apeló a desvirtuar el sentido original de los dichos y se lo asoció a la jerga popular de "armar" para referirse a los cigarrillos de marihuana. Como destaca Reguillo (2018) apropiarse de una imagen, es una manera sutil de darle la vuelta al poder.

Parte de la efectividad del meme como herramienta política para sentar posiciones se encuentra en su carácter de transgredir lo establecido y subvertir, en mayor o menor grado, el orden. En este sentido, encontramos similitudes con la caricatura, tal como ha sido formulado por Burkart, "[l]a caricatura se caracteriza por exagerar, "cargar" y deformar, rebajar y desenmascarar” (2014, p. 2). La autora recupera de Freud la acción de "volver cómica a una persona para hacerla despreciable, para restarle títulos de dignidad y autoridad", lo que produce "un sentimiento de superioridad tanto en el productor como en el consumidor de estas imágenes" (Bukart, 2014, p. 2). Según Soler, la capacidad de transgredir está asociada a que, en determinado contexto político, los sujetos se atreven a reírse incluso de imágenes o figuras que hasta entonces habían sido inmaculadas (Soler, 2015 , p. 42).
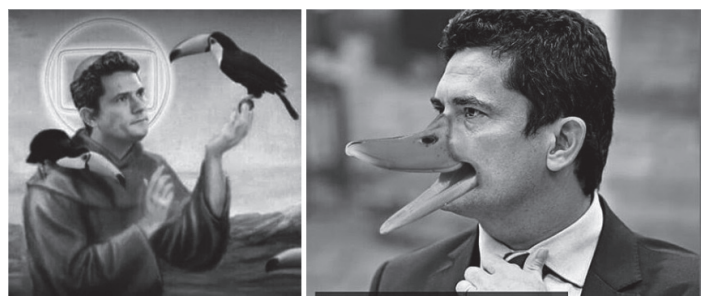

Figura 3. Sergio Moro. 
El salvador de los príncipes tucanos. En la Figura 3, Sergio Moro es ridiculizado como el salvador de los legisladores del PSDB acusados de formar parte de la asociación ilícita que intentó desarticular la operación "Lava Jato". Los militantes del PSDB son popularmente asociados a los tucanes. Además, se observa en la aureola de Moro el logo de la cadena de televisión "O Globo" que históricamente se ha posicionado en contra del PT.

\section{c. El humor sobre la pertenencia de clase y los consumos de los sectores dominantes}

Algunos memes juegan con la idea, muy arraigada en el imaginario popular, sobre la pertenencia de clase del expresidente argentino, Mauricio Macri, y su identidad de empresario. Como es sabido, Macri pertenece a una de las familias más ricas de Argentina y fue su padre, Franco Macri, quien generó la fortuna que luego él heredara. De este modo, la figura del presidente está asociada a los consumos de las elites y a la idea del "patrón", el que manda pero no se esfuerza tanto como sus empleados, sino que se toma vacaciones a su voluntad, ya que es "el dueño" (Figura 4). En la última campaña presidencial (2019), en la que Macri competía por la reelección en el cargo de presidente y fue derrotado en las urnas por el candidato Alberto Fernández (Frente de Todos), eligió al senador Miguel Ángel Pichetto como vicepresidente de su fórmula partidaria. En el juego de palabras de la Figura 4 se observa la leyenda compuesta por los apellidos de ambos candidatos, que remite a la noción de Macri como "cheto", en el sentido utilizado popularmente en Argentina en relación con las personas de alto poder adquisitivo.

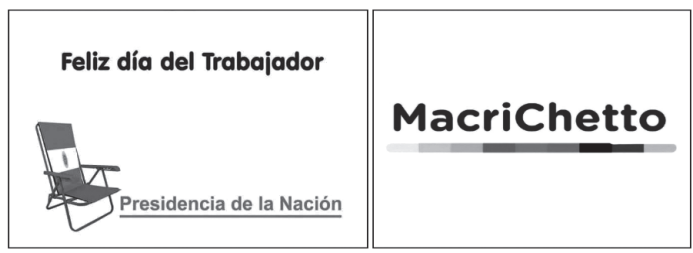

Figura 4. Reposera-MacriChetto.

Se evidencia entonces el carácter plebeyo del meme político como una de sus cualidades. En el contexto de producción de estos memes, el sistema dominante se puede ilustrar con los discursos del presidente Macri, quien se ha expresado en reiteradas oportunidades sobre los valores del esfuerzo individual, el trabajo -incluso durante los fines de semana o los feriados- y la meritocracia. Y en la vuelta que le da el ingenio popular, se representa al presidente con una reposera de descanso. El humor entretiene y distiende sí, pero es mucho más: puede ser también una forma de percepción y de crítica a lo establecido. 


\section{d. Memes virales, masivos y replicables}

Como mencionamos anteriormente, dos de los factores que inciden en la mayor o menor circulación de los memes son su replicabilidad y viralidad. Los memes se "viralizan", es decir se expande su circulación en breves períodos a partir del uso de los teléfonos celulares y así trascienden y contribuyen a configurar nuevas formas de interpretar la coyuntura política y social.

En muchos casos, los memes operan a partir de la visibilización de una situación en la cual la información es ignorada o tergiversada por los medios de comunicación dominantes y los discursos oficiales del gobierno. En este sentido, su carácter de virales, masivos y replicables se sostiene a partir de la generación de empatía y las coincidencias en las ideas previas de quien los recibe. Los aumentos de los servicios como gas, luz y agua, del transporte y los alimentos, así como también los índices de pobreza en alza, están presentes en las imágenes que se viralizaron. De hecho, uno de los ejes de la campaña electoral de Cambiemos en 2015 había sido la consigna "pobreza cero" que, articulada con una famosa foto de una campaña anterior (para Jefe de Gobierno de la Ciudad de Buenos Aires) en la que Macri posa con una niña en un basural, resume el mensaje que se quiere transmitir (aumento de la pobreza) al intervenir la mencionada foto con la figura de la niña multiplicada.

\section{e. Memes que trascienden las fronteras virtuales}

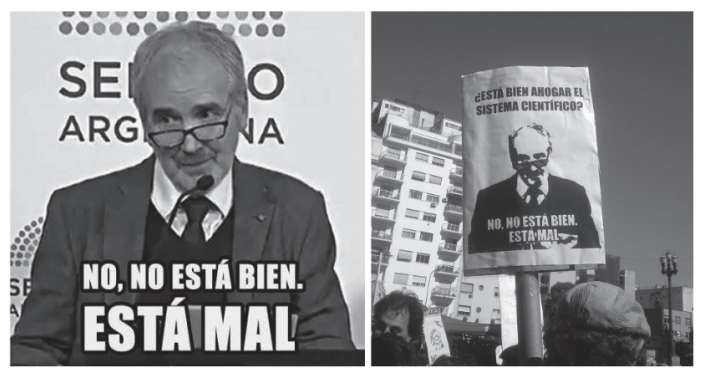

Figura 5. Kornblihtt.

Como mencionamos, los memes tienen la capacidad de sintetizar ideas y climas políticos y de ser rápidamente comprendidos por quienes los ven, siempre que compartan los códigos necesarios para descifrarlos. Tal fue el caso del meme ubicado a la izquierda en la Figura 5, surgido durante los debates en torno a la legalización de la Interrupción Voluntaria del Embarazo (ILE) que tuvieron lugar en Buenos Aires en mayo y junio de 2018. En ese contexto, una serie de figuras reconocidas de los campos científico, artístico, intelectual y de los movimientos sociales participaron prestando sus argumentos a 
favor o en contra del proyecto sobre el aborto. El biólogo Alberto Kornblihtt fue uno de los disertantes a favor de la ILE en el Congreso Nacional y, a partir del intercambio que mantuvo con la diputada Silvia Elías de Pérez, de posición contraria a la legalización, su intervención se volvería "viral":

- Elías de Pérez: O sea que usted está propiciando el uso eugenésico del aborto. - Kornblihtt: No. No es un uso eugenésico, es la voluntad de la madre.

- Elías de Pérez: Pero está claro que si de pronto detectan que es un niñito con síndrome de Down...

- Kornblihtt: No dije síndrome de Down. Dije una enfermedad incurable. ¿Usted cree que el síndrome de Down es una enfermedad?

- Elías de Pérez: Está bien.

- Kornblihtt: No. No está bien; está mal. (Brando, 9/1/2019).

La contundencia con la que el científico pronunció esta última frase fue tal que rápidamente comenzó a circular por las redes y entre quienes estaban siguiendo el debate. Unas semanas después, ya convertida en meme, la imagen (a la derecha en la Figura 5) fue utilizada en una jornada de protesta organizada por la comunidad científica frente al Congreso de la nación, en la que se demandaba más presupuesto para ciencia e investigación y de la que participó el propio Kornblihtt. El furor fue tal que unos meses más tarde la Revista Brando publicaría una entrevista titulada "Alberto Kornblihtt, el científico que se convirtió en meme". En este caso vemos cómo el meme, a partir de un episodio particular, pone en juego un discurso que es resignificado y reutilizado para otras causas, volviéndose parte de la estética de los repertorios de acción de protesta callejera.

Como destaca Arango Pinto (2015), los memes se oponen a la unidireccionalidad de los medios de comunicación tradicionales, principalmente, debido a la interactividad que posibilitan las redes sociales y que implican un diálogo mediado por la tecnología, que a su vez conlleva, no sólo una mayor participación de los usuarios en la selección de los contenidos, sino en la creación y la transmisión de estos.

\section{f. Lo plebeyo y lo artesanal como cualidades de los memes políticos}

Como vimos, el triunfo de Jair Bolsonaro en Brasil en 2018 tuvo fuertes repercusiones en la región. No sólo por tratarse de un candidato de la extrema derecha con discursos racistas, misóginos y autoritarios, sino que además se presenta a sí mismo por fuera de los partidos tradicionales que gobernaron dicho país desde la vuelta de la democracia en 1985. Además, se sumó a una serie de gobiernos que presentan, a grandes rasgos, similitudes sobre su línea política. En lo que ilustra el meme del perro que toma café mientras a su alrededor todo se está incendiando, encontramos una apropiación por parte de quien lo realizó, dado que el meme original no tiene las banderas de Argentina, Brasil ni Uruguay. En este sentido, se interpreta la intención de querer mostrar la "calma" de Uruguay, donde hasta el año 2019 gobernó el Frente Amplio, entre los dos países "en llamas", Argentina y Brasil, donde se encontraban gobernando las derechas representadas por Macri 
y Bolsonaro en el mismo año. Podemos agregar, por otro lado, la condición de artesanal del meme, que permite darle un nuevo significado, el cual se incorpora al original, a partir de sumarle las tres banderas de los países, con el objeto de resignificar la imagen para reflejar el clima de época. En palabras de Reguillo (2018), el meme "se puede resignificar una y otra vez, se recicla, aunque en cada uso hay una ganancia de sentido". La masificación del uso de las tecnologías y de las redes sociales, amplió las posibilidades del ingenio popular que, mediante cualquier herramienta digital, tiene a su alcance la capacidad para distorsionar, satirizar y viralizar la información circulante.

Como destaca Giménez (2016), la producción de memes resulta muy interesante para comprender la labor activa de los usuarios de internet, que no se posicionan como simples receptores, sino que acaban por involucrarse con el proceso creativo, vinculados con prácticas intertextuales que implican la reescritura y apropiación personal o colectiva de un contenido previo. A diferencia de las caricaturas en diarios y revistas tradicionales, cuya autoría es de un dibujante o caricaturista que cuenta con los derechos de autor, el meme que circula en internet se convierte en una obra colectiva que puede ser intervenida de manera anónima. Aun cuando el meme puede tener un autor conocido, con el paso del tiempo y con las transformaciones y los cambios estéticos que se le aplican en su "viralización", se va alejando de su autor original.

Por otro lado, encontramos memes que, desde su condición de "plebeyos", amparados en el anonimato, ironizan sobre las derechas en cuanto a que éstas poseen discursos despectivos sobre la actividad política, por considerarla un ámbito que está asociado a la corrupción. Esta representación negativa de lo político coincide con el contexto que describimos, sobre lo que Goldstein señala que "el tema de la corrupción había proporcionado un importante rédito electoral y se configuró históricamente como un factor de unificación en las campañas de los políticos de derecha" (2019, p. 21). Así, el meme remite a esta cuestión a partir de una síntesis irónica sobre quienes plantean "no soy de izquierda ni de derecha" y, luego de "revisar la jugada" tal como lo hacen los árbitros en los partidos de fútbol con el VAR, se dictamina que efectivamente plantear eso "es de derecha". Este análisis lleva además a reflexionar sobre las distintas formas de percepción de izquierda y de derecha y su enunciación, más o menos explícita, por parte de los sujetos.

\section{Conclusiones}

A lo largo de este trabajo hemos relevado y analizado las principales características del fenómeno reciente en el campo del humor, conocido como "memes". A partir del análisis de una selección de memes políticos que circularon masivamente a través de Whatsapp y Telegram en Argentina y Brasil entre 2015 y 2019, dimos cuenta de algunos de los mecanismos del humor utilizados para cuestionar lo establecido por los gobiernos de derecha de Mauricio Macri y de Jair Bolsonaro, y de las disputas por los sentidos producidos por algunas de las principales figuras de autoridad en ambos países.

Recapitulando lo desarrollado, los contenidos de los memes políticos, además de ser piezas de humor sobre distintos acontecimientos, contribuyen a producir y reproducir las 
agendas públicas de debate y expresan señales del clima político que predomina en cada coyuntura. A partir de la combinación de distintos elementos: el contexto de avance de las derechas a nivel regional, las tecnologías de comunicación -en especial las redes sociales de uso masivo- y el humor como herramienta de cuestionamiento a lo establecido; llevamos a cabo una reconstrucción de los sentidos disputados por los memes políticos sobre las derechas en Argentina y Brasil. Si bien no es posible determinar a partir del análisis de los memes cuál es el humor social imperante (y tampoco fue el objetivo de este trabajo) ni su alcance, los memes sí nos dan pistas sobre lo que algunos sectores de la sociedad consideran como "autoritario", como vimos en relación a las figuras de Bullrich y de Moro; cómo conciben a los líderes políticos según su pertenencia de clase; qué cualidades le otorgan al "ser de derecha", cómo se interpretan los acontecimientos políticos regionales, entre otros.

Asimismo, esbozamos una comparación entre los memes políticos y la caricatura política tradicional. Cabe aclarar que no consideramos que la caricatura y el meme sean estrategias humorísticas mutuamente excluyentes, sino que, por el contrario, ambos pueden coexistir en simultáneo. La exaltación de las cualidades que los asimilan y diferencian fue realizada con el objeto de distinguir a los memes políticos como una herramienta de humor que es propia de las condiciones de posibilidad de nuestra época y que, como tal, presenta algunas características que le son inherentes. En tal sentido, destacamos lo efímero y lo circunstancial -atados al contexto de producción- de los memes políticos, así como su objetivo de poner en ridículo a las figuras e ideas asociadas al poder, como dimensiones compartidas con la caricatura política. Mientras que la condición de "plebeyos" y artesanales -al ser producidos y modificados en su circulación por usuarios anónimos de las redes sociales-, su viralización y masividad, les confieren diferencias sustanciales con respecto a las caricaturas políticas.

Los casos analizados, Argentina y Brasil, dan cuenta de una primera aproximación, exploratoria, al estudio del humor político plasmado en los memes. Aquellos nos permitieron realizar un paneo superficial por algunas de sus cualidades, las que contrastamos con las principales características de la pieza humorística por excelencia, la caricatura. Al mismo tiempo, la comparación entre Argentina y Brasil arrojó algunas similitudes, como la ridiculización de las figuras de autoridad, Patricia Bullrich y Sergio Moro, aunque la cantidad de casos no pretende trazar generalizaciones, como mencionamos. Una posible línea de análisis, que podría ser considerada en trabajos futuros, debería indagar sobre la presencia (o ausencia) de la cuestión racial en la producción del humor político sobre las derechas en Brasil, además de los componentes de clase que ya vimos presentes en el caso argentino. Para finalizar, consideramos que este estudio puede ser ampliado a partir de una serie de interrogantes que, si bien no nos hemos propuesto responder en esta ocasión, resultan de interés para comprender el fenómeno de los memes políticos y el humor que circula por las redes sociales: ¿en qué medida estos memes trascienden las fronteras de lo virtual y qué repercusiones conlleva esto? Como vimos con el caso de la frase del científico Kornblihtt, algunos memes se vuelven parte del repertorio de protestas y, en ese sentido, nutren a las mismas de nuevas estrategias estéticas para llamar la atención de la opinión pública y de las autoridades, al tiempo que generan un impacto visual considerable. Otro aspecto que no ha sido analizado, aunque esperamos poder indagar en el futuro, tiene que ver con las 
estrategias del humor producido por las derechas: ¿con qué elementos ironizan los memes de las derechas? ¿A qué figuras eligen para satirizar y ridiculizar? Y, especialmente, ¿qué los diferencia del humor producido desde los sectores progresistas? Una posible respuesta que se esbozó de manera incipiente en nuestro trabajo se vincula con una reflexión más profunda sobre el humor político, que trasciende sus formas, y es su capacidad de transformarse en una herramienta de canalización de descontentos populares en contextos autoritarios y de transgresión de lo inmaculado de las figuras de poder, en palabras de Soler (2015).

\section{Bibliografía}

Arango Pinto, L. G. (2015) Una aproximación al fenómeno de los memes en Internet: claves para su comprensión y su posible integración pedagógica. En Comunicação, Mídia e Consumo 12 (33), pp. 110-132, São Paulo.

Burkart, M. (2009). Horcas, guillotinas y verdugos. Revista Eadem Utraque Europa 5 (9), pp. 155-190. Escuela de Humanidades de la UNSAM- Miño y Dávila Editores.

Burkart, M. (2014). Caricatura política en el Cono Sur: entre la radicalización política y las dictaduras militares. En Revista Contemporânea, Dossiê Convidado: Caricatura Política en el Cono Sur 2 (4).

Chagas, V.; Freire, F. A.; Rios, D. y Magalhães, D. (2017). A política dos memes e os memes da política: Proposta metodológica de análise de conteúdo de memes dos debates eleitorais de 2014. Intexto 0 (38), pp. 173-196. Disponible en: https://doi.org/10.19132/18078583201738.173-196

Corso, P. (2019). Alberto Kornblihtt, el científico que se convirtió en meme. Brando. Disponible en: https://www.lanacion.com.ar/lifestyle/alberto-kornblihtt-cientifico-seconvirtio-meme-nid2209376

Dawkins, R. (1979). El gen egoista. Barcelona: Labor.

García Huerta, D. (2014). "Las imágenes macro y los memes de internet: posibilidades de estudio desde las teorías de la comunicación”. En Paakat, revista de tecnología y sociedad 4 (6), marzo-agosto.

Giménez, F. (2016). Calling memes memes is a meme: un acercamiento al mundo del meme de internet. En Fabiani, N. y Brutocao, M. (comps.) Actas de las XIX Jornadas Nacionales de Estética y de Historia del Teatro Marplatense: los ecos de Eco, pp. 216-224. Mar del Plata: Universidad Nacional de Mar del Plata.

Reguillo, R. (Entrevistada). (4 de diciembre de 2018). Todo es fake: El uso político del meme [Audio en podcast]. Disponible en: https://open.spotify.com/ show/4OYEg0LP4Cg43PAVvSXa45

Romano, E. (1990): "Breve examen de la historieta”. En Ford, A.; Rivera, J. y Romano, E. (1990 [1985]). Medios de Comunicación y Cultura Popular. Buenos Aires: Legasa.

Solano, E. (2018). Crise da democracia e extremismos de direita. Análise, $N^{\circ} 42$, Friedrich Ebert Stifting, Brasil.

Soler, L. (2015). ¿De qué se ríe el pueblo? La crisis del régimen stronista en las caricaturas 
del Semanario del Partido Revolucionario Febrerista en Paraguay (1984-1987). Historia Actual Online 38 (3), pp. 37-49

Soler, L. (2017). Combatir el comunismo con humor. El diario Patria durante la celebración del XII ${ }^{\circ}$ Congreso Anual de la Liga Anticomunista Mundial en Paraguay (1979). Anuario IEHS 32 (2), Instituto de Estudios Histórico-Sociales, Facultad de Ciencias Humanas, Universidad Nacional del Centro, Tandil, pp. 193-220.

Urresti, M., Linne, J. y Basile, D. (2015). Conexión total. Buenos Aires: Ediciones del Aula Taller.

Vélez, J. (2012). “Las memes de Internet y su papel en los medios de comunicación mexicanos". En Memorias del XXIV Encuentro Nacional de la AMIC. Saltillo, México DF: AMIC.

\begin{abstract}
During recent years, the massive use of new technologies enabled immediate communication and information channels, which, at the same time, had consequences on the forms of production, circulation and consumption of humor. Among others, different forms of humor were popularized, the well-known "memes", which consist of images intervened as a parody, satire or ridicule of public figures, from presidents to religious leaders and different political spaces referents.

The objective of this article is to analyze the contents of right-wing memes as an expression of social moods and political climates in Argentina and Brazil between 2015 and 2019. In particular, we worked with memes that circulated through social networks such as Twitter, Instagram and Facebook, between 2015 and 2019 in Brazil and Argentina. To organize our analysis, we selected some political events that had the greatest media impact during the period.

Finally, we outline a reflection on political memes as new humorous formats, the moments in which they arise, their immediacy and short-term effect and their contribution to the reproduction of certain social moods.
\end{abstract}

Keywords: memes - political humor - Brazil - Argentina.

Resumo: Nos últimos anos, o uso massivo de novas tecnologias possibilitou canais de comunicação e a circulação da informação imediatamente, o que, por sua vez, teve consequências para as formas de produção, circulação e consumo de humor. Entre outras, as formas de humor se popularizaram, os conhecidos "memes", que consistem em imagens que intervêm como paródia, sátira ou ridículo de figuras públicas, desde presidentes a líderes religiosos, passando por referências de diferentes espaços políticos.

O objetivo deste trabalho é analisar o conteúdo de memes sobre as direitas como expressão de humores sociais e climas políticos na Argentina e no Brasil entre 2015 e 2019. Em particular, foram realizados trabalhos com memes que circulavam em redes sociais de uso em massa, como o Twitter, Instagram e Facebook, entre 2015 e 2019 no Brasil e na Argentina. Para organizar nossa análise, selecionamos alguns dos eventos políticos com maior impacto na mídia durante o período. 
Para finalizar, esboçamos uma reflexão sobre memes políticos como novos formatos humorísticos, os momentos em que surgem, seu imediatismo e efeito a curto prazo e sua contribuição para a reprodução de humores sociais.

Palavras-chave: memes - humor político - Brasil - Argentina.

[Las traducciones de los abstracts fueron supervisadas por el autor de cada artículo] 